\title{
SOBRE LA FUNCIÓN QUE DEBE CUMPLIR EL ABOGADO Y LA MISIÓN QUE TIENE ASIGNADA
}

\author{
Rodrigo Padilla* y Agustina Frías
}

\section{RESUMEN}

El trabajo trata sobre la misión que le corresponde al abogado cumplir en nuestra sociedad. Elegimos este tema habida cuenta la trascendencia que el mismo representa y el norte que busca la Universidad Femenina del Sagrado Corazón -que no es otro que formar personas íntegras, tanto en lo científico, cuanto en lo moral-, para cuya Revista estamos otra vez orgullosos de poder ser humildes colaboradores. Se hace concreta mención al reciente Código de Ética del Abogado, aprobado por la Junta de Decanos de los Colegios de Abogados del Perú, además de otros cuerpos normativos deontológicos similares que rigen en países como Argentina, México y España, e incluso el Código de Deontología de los Abogados de la Unión Europea; también se recurre a una seleccionada doctrina con vocación de cierta universalidad, habida cuenta que la misión que tienen asignada los letrados es tanto trascendente para el orden social, cuanto cimentada en pilares homogéneos en las diversas naciones -al menos en las occidentales-.

\section{PALABRAS CLAVE}

Abogado - Misión del abogado -Función del abogado - Código de Ética del Abogado - Deontología forense.

\begin{abstract}
This paper deals with the mission lawyers play in our society. We chose this topic given its importance and the ultimate goal of Universidad Femenina del Sagrado Corazón, which is simply to form accomplished individuals, both in science and in moral terms, to whose journal we are once again proud of being humble collaborators. Specific reference is made to the Code of Ethics for Lawyers, recently approved by the Board of Deans of the Bar Associations of Peru, and other similar regulatory bodies governing ethics in countries like Argentina, Mexico, and Spain, including the Code of Conduct for European Lawyers; it also refers to selected doctrine with some universal vocation, given the mission lawyers are called upon to fulfill so critical for social order and rooted on the homogeneous pillars of various nations-at least in different Western communities.
\end{abstract}

\section{KEY WORDS}

Lawyer - Attorney‘s Mission -Attorney’s Duties - Code of Ethics of Lawyers- Ethics.

* Autor de libros, capítulos de libros y artículos sobre este tema. Conferencista. Profesor a cargo de las siguientes cátedras universitarias: Derecho Privado II (Obligaciones y Responsabilidad Civil); Derecho Privado IV (Derechos Reales y Propiedad Intelectual), y Derecho Registral. Director del Curso de Posgrado en Notariado, en diversas Universidades argentinas. Sobre esta cuestión puede cotejarse, de su autoría, "El rol social del abogado", La Ley -Noroeste-, año 8, número 8, septiembre de 2004, pág. 1401 y s.s.; y un libro titulado Misión, derechos, deberes y responsabilidad del abogado, Biblioteca Iberoamericana de Derecho, Reus, Madrid -España-, y Ubijus, DF -México-, 2013, págs. 35 y s.s. 
Antes de tratar sobre la función y la consecuente misión ${ }^{1}$ que le compete al abogado, conviene recordar que "abogar" viene del latín advocãre y cuya primera acepción, según el diccionario de la Real Academia Española en su vigésima segunda edición del año 2001 (la vigésima tercera edición, que no tiene modificaciones en este aspecto, se encuentra por aparecer al momento de imprimirse la presente revista), hace referencia a la defensa en juicio, sea por escri- to o de palabra. Inmediatamente después, se define al término de esta forma: "interceder, hablar en favor de alguien". En este sentido, la Fe Cristiana suele recordarnos que la Virgen María es "Abogada" nuestra.

Por supuesto que el mismo origen latino tiene el vocablo "abogado"2 puesto que proviene de advocatus ${ }^{3}$ y se define en el citado cuerpo como aquel "Licenciado o doctor en derecho que ejerce profesionalmen- te la dirección y defensa de las partes en toda clase de procesos o el asesoramiento y consejo jurídico".

No se crea, empero, que la definición transcripta no es tan "técnica", pues incurriremos en error. Efectivamente, la vigente Ley Orgánica del Poder Judicial de España (Ley 6/85 del 1 Julio, modificada por Ley Orgánica 19/2003 del 23 de diciembre) la sigue prácticamente en forma literal, al expresar en su artícu-

Normalmente se utilizan como sinónimos los términos "función” y "misión", por lo menos al tratar la temática que nos ocupa. De esta asimilación conceptual es dable remarcar que la "función" del abogado alude o se dirige a la naturaleza práctica, es decir al ejercicio en sí mismo, "mientras que la 'misión' se aproxima al elevado contenido de una finalidad. En este caso, la búsqueda de una solución “justa”, anota con agudeza CIPRIANO, Néstor Amílcar (1990). Misión y jerarquía de abogados y jueces y otros estudios de derecho. Buenos Aires: Depalma, p. 17. Es decir, que la palabra "misión" ofrece un contenido más amplio que "función". Con criterio parecido también se ha afirmado que dada las características especiales del quehacer del abogado "más que función es misión, por su cualificado significado en el ámbito de la comunidad. Contribuye... a una convivencia más humana, en la que la justicia y, por ende, la paz, y hasta quizá la solidaridad se manifiestan. Viene a atender una de las necesidades básicas de la persona: disponer de una asistencia jurídica idónea", conf. MUÑOZ CAMPOS, Juan (1989). “La responsabilidad civil de los abogados y procuradores”, en Centenario del Código Civil, II, Universidad Popular, Francisco Rico Pérez (Director y Coordinador), Extensión Universitaria de la Facultad de Ciencias Políticas, (Universidad Complutense de Madrid) y Universidad de Alicante, p. 348. Podríamos concluir, entonces, que el abogado cumple una función encaminada a realizar o alcanzar una elevada misión dentro de la sociedad. En pocas palabras, la función es el medio para alcanzar la misión, su fin.

2 En el Digesto, título 1 y 2 del libro III, se señala que "El papel de un abogado es exponer ante el juez competente su deseo o la demanda de un amigo, o bien combatir la pretensión de otro".

3 Comenta el gran procesalista Couture respecto de la etimología de este vocablo que proviene "Del latín advocatus, -i 'el que asiste a un litigante con su consejo o presencia'. El latín advocatus no designaba propiamente a un abogado, sino más bien a un patrono, un tutor o simplemente a una persona influyente que asumía la defensa de otra, de una institución o de una ciudad, mientras que el abogado profesional se denominaba en latín clásico causidicus, patronus causae y, en baja época, también adsertor o assertor. Textualmente significa 'llamado a asistir' o 'llamado junto a' (es participio pretérito pasivo de advoco,- are 'llamar junto a', de ad- 'hacia'- voco, -are 'llamar'). El sustantivo castellano no es, como pareciera, participio del verbo castellano abogar, sino que al revés, el verbo fue formado, al menos con su acepción actual, a partir de abogado". Ver: COUTURE, Eduardo J. (1997), Vocabulario Jurídico, con especial referencia al derecho procesal positivo vigente uruguayo, edición al cuidado de Jorge Peirano Facio y José Sánchez Fontáns, $6^{a}$ reimpresión. Buenos Aires: Depalma, p. 58, término “abogado". Además, puede consultarse en GATTARI, Carlos Nicolás (1998). Abogado. Escribano. Juez. Mediador. Registrador. Buenos Aires: Depalma, p. 24. Tal autor sigue las magníficas enseñanzas que impartió el mencionado jurista uruguayo. También se ha señalado que la antigua Grecia desconoció a los abogados y los acusados debían defenderse por sí mismos. Sólo a partir del siglo V, en algunos procesos importantes, "oradores (logógrafos) incluso como Demóstenes, redactaban un alegato. La Roma republicana conoce el papel de amigos (advocati) que asisten a las partes del proceso en los pretorios, e incluso de los abogados (patronus, tutor, orator) como profesión honorífica que otorga fama e influencia y da acceso a los grados en la carrera de los honores. Bajo el Imperio, la función de abogado pierde prestigio y ya no permite el acceso a las funciones públicas, pero se vuelve remunerable. Los abogados desaparecen prácticamente en la Alta Edad Media de Europa, y no reaparecen sino hasta el siglo XIII; con el renacimiento del derecho romano y la afirmación de la justicia real", conf. KAPLAN, Marcos (1999). "El abogado y la sociedad", en El papel del abogado, Instituto de Investigaciones Jurídicas. México: UNAM, Universidad Americana de Acapulco, Porrúa, p. 105.

Además puede verse la excelente obra de ESCRICHE, Joaquín (1907). Diccionario razonado de Legislación y Jurisprudencia. Novísima edición, corregida notablemente, y aumentada con nuevos artículos, notas y adiciones sobre el derecho americano, por don Juan B. GUIM, Librería de la Vda. de C. Bouret, París-México, p. 16, voz "abogado", quien explica que "Esta voz viene del adjetivo latino advocatus, que significa llamado, porque entre los romanos en los negocios en que pedían conocimiento de las leyes llamaba cada cual en su socorro á los que hacían un estudio particular del derecho. También eran designados con los nombres de patronos y defensores, porque tomaban bajo su protección a las personas, encargándose de la defensa de sus intereses, de su honor ó de su vida ; y, al mismo tiempo, se les daba alguna vez el título de oradores, cuando se les veía desplegar con calor toda la fuerza de la elocuencia perorando por sus clientes. Todas estas denominaciones convienen igualmente entre nosotros á los que ejercen la profesión de la abogacía; y se les da además por nuestras antiguas leyes la de voceros, , porque usan de su oficio con voces y palabras". 
lo 542 -en la normativa anterior era el artículo 436- que "corresponde en exclusiva la denominación y función de abogado al licenciado en Derecho que ejerza profesionalmente la dirección y defensa de las partes en toda clase de procesos, o el asesoramiento y consejo jurídico" 4 .

También en el Estatuto General de la Abogacía española ${ }^{5}$-norma corporativa básica y vinculante para todos los Colegios de Abogados de España- se sigue literalmente la citada definición, agregando que se consideran abogados 'ejercientes' aquellos que "incorporados a un Colegio español de Abogados en calidad de ejercientes y cumplidos los requisitos necesarios para ello, se dedican de forma profesional al asesoramiento, concordia y defensa de intereses jurídicos ajenos, públicos o privados" (ver artículo 6 y artículo $9.1 \mathrm{del}$ mencionado Estatuto, aprobado por Real Decreto 658/2001 del 22 de junio, que derogó al Real Decreto 2090/1982 del 24 de julio).

Y ya que estamos con las definiciones, en una conocida sentencia, el Tribunal Supremo español define al abogado como "aquella persona que se incorpora a un Colegio de Abogados y en despacho, propio o compartido, efectúa los actos propios de esa profesión, tales como consulta, consejo y asesoramiento, arbitrajes de equidad o Derecho, conciliaciones, acuerdos y transacciones, elaboración de dictámenes, redacción de contratos y otros actos jurídicos en documentos privados, práctica de partición de bienes, ejercicio de acciones de toda índole ante las diferentes ramas jurisdiccionales, $y$, en general, defensa de intereses ajenos, judicial o extrajudicialmente"6.

No vamos a señalar aquí las deficiencias técnicas ${ }^{7}$ que adolecen las citadas definiciones. Tampoco nos incumben los requisitos que son necesarios para que un profesional $^{8}$ pueda ser considerado "abogado" en el

4 Y ya que estamos con el ordenamiento español, se ha señalado que aunque el Fuero Juzgo (Ley III, Tít. III, libro II), el Fuero Viejo (Tít. I, Libro III), el Espéculo (Tít. IX, Libro IV) y el Fuero Real (Tít. IX, Libro I) dedicaron varias normas a los abogados (voceros), "fue en las Partidas cuando se organiza, bajo el modelo romano, lo concerniente a los abogados, y desarrolla esta materia en el Título VI de la Partida III, donde se facilita su concepto y se les considera como caballeros (miles legalis), se fijan los requisitos de su capacidad, los deberes y derechos, se tasan los honorarios, se conmina con la pérdida del oficio a quien celebrara el pacto de quota litis y se señalan otras penas al que no cumpliera sus obligaciones", GARCÍA VARELA, Román, "La conducta desidiosa del abogado y la responsabilidad civil", en La Ley (España), D-324, p. 2265, diario 4692 de 14 de diciembre de 1998. Además, recuerda el citado autor que el Ordenamiento de Montalvo (Título XIX, Libro II), las Ordenanzas de Medina y las Ordenanzas de los Abogados del año 1495 completaron dicha regulación en forma casuística; “posteriormente la Novísima Recopilación (Título XXII, Libro V) reunió todas las disposiciones a la sazón vigentes, y ya no se legisló más en este espacio hasta la Ley Orgánica del Poder Judicial de 15 de septiembre de 1870”, art. cit., idéntica página.

5 Debemos resaltar que "El Nuevo Estatuto General de la Abogacía vio la luz después de un largo y laborioso proceso de elaboración y como primer resultado del Pacto por la Justicia suscripto por las principales fuerzas políticas del Estado y de los denominados agentes de la Justicia, en el que tanto tuvo que ver la postura unánime de la abogacía española, manifestada a través de los máximos representantes de sus órganos rectores que, incluso, brindaron la sede del Consejo General para que se tuvieran las primeras reuniones que posibilitaron, más tarde, el pacto", conf. GAY MONTALVO, Eugenio (2003). "El largo camino hacia un nuevo Estatuto General de la Abogacía: novedades y permanencias". En: Comentarios al Estatuto General de la Abogacía Española, Madrid: Thomson Civitas, p. 15.

6 Sentencia del Tribunal Supremo del 10 de Noviembre de 1990, Ponente Excmo. Sr. Luis Vivas Marzal. Ver, además, CARNICER DÍEZ, Carlos (2003). “Normas deontológicas”, en Comentarios al Estatuto General de la Abogacía Española. Madrid: Thomson Civitas, p. 200.

7 En especial, la definición que traía el anterior Estatuto, de la que se dijo, por ejemplo, que el hecho de establecer como condición que el abogado tenga un "despacho profesional" deja de lado a los abogados que están bajo algún régimen de dependencia, o los que trabajan en el seno de una empresa y por tal motivo carecen de un despacho 'propio', tal como pareciera exigir la derogada norma. También se señaló, con acierto, que no necesariamente debe ser 'ajeno' el interés jurídico defendido por el abogado para que pueda ser considerado como tal. Bien puede tratarse de un interés personal. Este último defecto no fue superado en la nueva normativa, tal como puede observarse con nitidez. Ver en este aspecto un libro cuya lectura recomendamos. Nos referimos a SERRA RODRÍGUEZ, Adela (2001). La Responsabilidad Civil del Abogado. $2^{\text {a }}$. Ed. Navarra: Editorial Aranzadi S.A., p. 351.

8 Respecto de la noción de "profesional", es claro que la misma ha estado signada de una marcada multivocidad. Ello surge evidente debido a los debates planteados cuando se le pretende delimitar un régimen especial de responsabilidad civil. Las concepciones varían según se entienda a tal concepto en sentido amplio o restringido. El concepto amplio supone la concurrencia de "algunas" de estas notas distintivas en su desempeño: habitualidad, reglamentación, habilitación, presunción de onerosidad, autonomía técnica y, en su caso, sujeción a la colegiación, sometimiento a las normas éticas y potestades disciplinarias, no siendo imprescindible el título profesional universitario. Dentro de esta conceptualización amplísima ingresan los rasgos constitutivos de la noción de "profesional liberal", cuestión también objeto de debates. Sobre el particular, en las IV Jornadas Sanjuaninas de Derecho Civil, realizadas en 1989, se consideraron como notas distintivas de la "profesionalidad" en sentido lato, entre otras, la condición de "experto" en un área del saber (científico, 
sentido propio del concepto 9 y pueda aplicársele toda una normativa particular. En definitiva, estas condiciones dependerán del ámbito en donde se ejerza tal noble profesión.

Lo que sí queremos resaltar aquí es que tanto en el lenguaje común cuanto en el propio de la 'ciencia del Derecho' se considera al abogado como defendiendo intereses particulares, sean éstos ajenos o propios, ora públicos ${ }^{10}$, ora privados. Es decir se le contempla principalmente como profesional que está al servicio de intereses bien diferenciados. Su rol debe ser completamente parcial ya que debe asesorar, representar, patrocinar, aconse- jar o defender a una persona determinada. Se tiene en cuenta en primer orden un interés individual.

No creemos en lo más mínimo que sea exagerado decir que la gran mayoría de nuestros colegas piensan de esta manera. Según su óptica nuestra "misión" en la sociedad no radica en beneficiar a ésta, sino tan sólo a esa persona -cliente- que acude a nuestro auxilio.

Se piensa, erróneamente, que el sistema está organizado de tal manera que su razón de ser estriba justamente en bregar por un interés particular sin atender en grado alguno a otro tipo de finalidad.
Ahora bien, esta forma de contemplar a nuestra profesión ¿es la correcta?

Creemos que no, pues es, al menos, incompleta. Olvida otra faceta, sin duda más importante, que le es propia a esta profesión. No se tiene presente que el abogado es un "auxiliar" de la Justicia"11 y debe prestar su labor en pos del esclarecimiento real de los hechos, luchando por el triunfo de la verdad ${ }^{12}$ que, en rigor de principios, tiende a consolidar el Estado de Derecho.

De esta función (en puridad, "misión") -eminentemente social ${ }^{13}$ - muchos reniegan en beneficio aparente de su parte

técnico o práctico), habitualidad, reglamentación, habilitación, presunción de onerosidad; y, en especial, con relación a los "profesionales liberales": autonomía técnica, sujeción a normas reglamentarias y éticas. De esta forma se resaltaban las notas propias que caracterizaban al profesional liberal como especie. En otro sentido, es claro que debemos observar cada reglamentación en especial para constatar si a dicho profesional liberal -en nuestro caso el abogado- le será de aplicación el régimen particular de protección al consumidor, cuestión un tanto ajena a nuestro estudio. Para ello derivamos, entre otros, y a quienes venimos siguiendo en esta nota: FRESNEDA SAIEG, Mónica y FRUSTAGLI, Sandra A. "Las prácticas abusivas en la ley de Defensa del Consumidor: implicancias en orden a la responsabilidad profesional del abogado", en RCyS 2009-IX, pág. 16 y s.s. y en La Ley on line del 24-02-2010.

9 Por otro lado, coincidimos con Ossorio en cuanto a que el "verdadero" abogado es el que "ejerce permanentemente (tampoco de modo esporádico) la Abogacía. Los demás serán Licenciados en Derecho, muy estimables, muy respetables, muy considerables, pero Licenciados en Derecho, nada más", OSSORIO, Ángel (1997). El alma de la toga, Buenos Aires: Librería El Foro, p. 24. Con ello el notable jurista y ex Decano del Colegio de Abogados de Madrid (además de ex Gobernador de Barcelona) quiso significar que la abogacía no es una consagración académica, sino una concreción profesional a quien dedica su vida a dar consejos jurídicos y pedir Justicia.

10 El caso del abogado del Estado: Si bien defiende un interés “público" lo es de una persona determinada, por ello le acentuamos esa nota de 'parcialidad'. Además, es sabido que el Estado bien puede desenvolverse en la esfera privada, e incluso puede adoptar formas jurídicas propias de esa naturaleza.

11 Por cierto que, más que "auxiliar" de la Justicia -como se determina en la generalidad de las legislaciones y se hace eco nuestra doctrina-, el abogado es una pieza fundamental en el sistema judicial; por ello se expresó, con acierto, que "el abogado no es un mero auxiliar de la justicia. La palabra 'auxiliar' no da la dimensión de su tarea, pues parece referirse a un grado menor. El abogado no es un auxiliar sino una presencia relevante en el proceso. Integra la estructura de su funcionamiento. El patrocinio obligatorio que consagra la ley procesal representa la necesidad ineludible de la asistencia técnico-científica. Y ello se conecta con el derecho de defensa, de raíz constitucional”. CIPRIANO, Néstor Amílcar, Misión y jerarquía de abogados y jueces..., ob. cit., pág. 22. Con criterio parecido se ha señalado que el abogado "es un colaborador necesario de la función jurisdiccional al que se le confía la defensa efectiva de los derechos individuales y colectivos; de ahí que las consecuencias de sus errores sean tan graves", CRESPO MORA, María Carmen (2005). La responsabilidad del abogado en el Derecho Civil. Navarra: Thomson Civitas (Editorial Aranzadi S.A.), p. 31. La cursiva es nuestra. Sobre el particular, reza el artículo tercero, segunda parte, del Código de Ética del Abogado para el Perú -aprobado por la Junta de Decanos de los Colegios de Abogados del Perú- que "La probidad e integridad de la conducta del abogado, cualquiera fuere el ámbito donde se desempeñe, es esencial para el adecuado funcionamiento del sistema de justicia, la vigencia del Estado de Derecho y la vida en sociedad. La transgresión de los principios éticos agravia a la Orden".

12 Recordemos que el lema de la prestigiosa Universidad de Harvard -para muchos la mejor en el orbe actualmente- es, precisamente, veritatis.

13 Señaló el estimado profesor Mosset Iturraspe que las profesiones (en particular “nuestra profesión”) “dejan de ser liberales para convertirse en sociales, por su eco o resonancia en la vida de la comunidad. El hacer del profesional no queda ahora liberado a su iniciativa, imaginación, preocupación o ciencia...; sus semejantes tienen derecho a no ser defraudados 
especial. Algunos cortos de vista se estiman mejores abogados porque son capaces de presentar la verdad disfrazada, o porque su oratoria y elocuencia son aptas para marear al más despierto de los jueces, o porque su cliente, en definitiva, obtiene más provecho de la situación de lo que los límites moral y jurídico le establecieron ${ }^{14}$.

Olvidan, por ejemplo, que el reciente Código de Ética del Abogado para el Perú, aprobado el 14 de abril del 2012 por la Junta de Decanos de los Colegios de Abogados del Perú (que consagra reglas obligatorias para todos los abogados inscritos en los Colegios de Abogados de la República) dispone que la Abogacía cumple una función social al servicio del Derecho y la Justicia. Y que "su objetivo esencial es la convivencia social de los hombres como fuente fecunda de paz, libertad, progreso y bienestar general" (conf. art. 2). Y en cuanto a la "misión" de nuestra profesión sostiene que "La abogacía tiene por fin la defensa de los derechos de las personas y la consolidación del Estado de Derecho, la justicia y el orden social" (conf. art. 3ero).

En este orden de ideas, el Código de Ética de los Abogados que rige en el ámbito Federal de la República Argentina, en su artículo 6, proclama que "Es misión esencial de la abogacía el afianzar la justicia y la intervención profesional del abogado, función indispensable para la realización del derecho". También reza que el abogado debe "preservar y profundizar el Estado de Derecho fundado en la soberanía del pueblo y su derecho de autodeterminación" (artículo 7) y que "es consustancial al ejercicio de la abogacía la Defensa de los Derechos Humanos" (artículo 8).

En idéntico sentido, aunque menos gráfico, el Código de Deontología de los Abogados de la Unión Europea establece en su Preámbulo que el abogado cumple un papel esencial en la sociedad y que "Sus obligaciones no se limitan al fiel cumplimiento de lo encomendado, en el ámbito de la legislación aplicable. En un Estado de Derecho, el Abogado debe servir a los intereses de la Justicia, así como los derechos y libertades que se le han confiado para defenderlos y hacerlos valer"15.

En otra oportunidad hablaremos sobre la relación entre el orden normativo moral con el jurídico. Cumple aclarar que también para los positivistas valen las reglas recién sentadas.

Más patente es el asunto si tenemos presente que el Estatuto General de la Abogacía española también nos habla de la "función social" que corresponde a la abogacía y la colaboración que se debe prestar en la promoción y administración de la Justicia. En efecto, en su título 1ero, artículo 1.1, nos expresa que la abogacía es una profesión libre e independiente que "presta un servicio a la sociedad en interés público"16.

También la Constitución Federal brasilera del año 1988 en su artículo 133 proclama al abogado como indispensable a los efectos de la administración de la Justicia, siendo inviolable por sus actos y manifestaciones realizados con motivo del ejercicio de su función.

Con este mismo parecer, podemos observar el Preámbulo del Código de Ética mexicano que nos señala que "En una sociedad fundada en el respeto a la Justicia, el abogado tiene un papel fundamental. Su misión no se limita a ejecutar fielmente un mandato en el marco del Derecho. En un Estado de Derecho, el Abogado es indispen-

y de ahí que se les competa el deber de un ejercicio idóneo, probo, leal y honesto. En que ello ocurra hay intereses superiores, que exceden del interés del cliente, la convivencia en paz y armonía, para el logro del bien común, aparecen comprometidos", MOSSET ITURRASPE, Jorge, "Responsabilidad profesional del abogado por daños en el ejercicio de su misión", en La Ley, 1980-C, p. 488 y s.s.

14 Con criterio parecido se ha señalado que "Aunque el vulgo ignaro y prostituido suele creer que la gracia del abogado está en hacer ver lo blanco negro, la verdad es exactamente la contraria. El abogado está para que lo blanco deslumbre como blanco y lo negro entenebrezca como negro. Somos voceros de la verdad, no del engaño. Se nos confía que pongamos las cosas en orden, que procuremos dar a cada cual lo suyo, que se abra paso la razón, que triunfe el bien", OSSORIO, ANGEL. Op. cit., p. 127.

15 Conf. Preámbulo, artículo 1., 1. "La función del Abogado en la sociedad”. Tal Código de Ética de la Unión Europea ha sido adoptado por los representantes de las 18 delegaciones de la Comunidad Europea y del Espacio Económico Europeo, en la Sesión Plenaria en Estrasburgo el 28 de octubre de 1988 y modificado en las Sesiones Plenarias de 28 de noviembre de 1998 y 6 de diciembre de 2002.

16 Respecto de la función social que cumple el abogado (más bien la "abogacía”) en España recomendamos el excelente trabajo de CARNICER DíEZ, Carlos. (2003). “Normas deontológicas”, en Comentarios al Estatuto General de la Abogacía Española. Madrid: Thomson Civitas, p. 189 y s.s. 
sable para lograr el respeto y cumplimiento de la Justicia y de los justiciables, pues tiene la obligación de defender sus derechos y libertades; es por lo tanto el asesor y defensor de su cliente, y en todo momento deberá buscar la prevalencia de la Justicia"17.

Existe otro ordenamiento legal que directamente proclama que el ejercicio profesional de la abogacía entraña una "función pública”. En efecto, el artículo primero de la Ley Provincial № 5233 (Adla, XLI-A, 1228) que regula el ejercicio profesional de la abogacía en la Provincia de Tucumán -República Argentina- expresa que "La abogacía es una función social al servicio del derecho de la Justicia. Su ejercicio es una función pública, pero de desempeño particular o privado"18.

No entraremos en inútiles disquisiciones en torno a si el concepto "función pública" es del todo aplicable. Sí resaltaremos que estos textos normativos, como tantos otros, hacen hincapié en la función social (y consecuente "misión") que deben los abogados cumplir.
En efecto, no es tan sólo la defensa de un interés particular lo que conforma la esencia de la profesión. Con tal inteligencia VIGO $^{19}$ señala que el abogado debe ser responsable, lo que implica que al defender el interés encomendado no debe dejar de lado las exigencias del bien común. Por ello "se admite pacíficamente que aunque los abogados patrocinen los derechos privativos de sus clientes, están también en alguna medida participando del "munus", o desempeñando un cometido cuasi público, ya que cumplen una indudable y trascendente función social, al cooperar con el Estado para que se eliminen o compongan los conflictos existentes entre los particulares" 20 .

En idéntico sentido ha señalado el ilustre profesor florentino Piero CALAMANDREI que "la abogacía responde, aún en el Estado autoritario, a un interés esencialmente público, tan importante como el interés a que responde la magistratura; jueces y abogados son por igual órganos de la justicia, servidores igualmente fieles al Estado, que les encomienda dos momentos inseparables de la misma fun- ción"21. También hablando del Derecho italiano ha expresado LEGA que sociólogos y juristas están de acuerdo en admitir que la abogacía cumple una notable función social. De hecho, el legislador configuró a esta profesión como un "servicio de necesidad pública (art. 359 del Cód. Pen.) y como ministerio, función y colaboración a la administración de justicia (Ley forense)"22.

En esta senda, podemos afirmar con CUETO RÚA, que "Tanto el juez como el abogado son llamados por su vocación, a realizar los valores que dan sentido a sus vidas como hombres de derecho: el orden y la seguridad, para abrir el camino de la acción humana; la paz y el poder, para unir espíritus y movilizar energías; la cooperación y la solidaridad para enriquecer la vida de otros con el aporte de la propia y la justicia, para alcanzar armonía individual y social y racionalidad en el comportamiento"23.

Y no está de más recordar que el Poder Judicial es el más trascendental de los Poderes del Estado puesto que, como expre-

17 Ver: Código de Ética de los Abogados de México del año 1997, 1. Preámbulo, 1.1. La misión del abogado.

18 También resalta esta normativa particular LÓPEZ HERRERA, Edgardo (2006). Teoría General de la Responsabilidad Civil. Buenos Aires: Lexis Nexis, p. 543.

19 VIGO, Rodolfo Luis (h) (1979). Ética del Abogado. Conducta procesal indebida. Buenos Aires: Abeledo-Perrot, p. 143, mandamiento 6: "SÉ RESPONSABLE".

20 Conf. TRIGO REPRESAS, Félix A. (1998). “Normas legales y principios éticos en el ejercicio de la abogacía”, en Ética y Derecho, en homenaje al Dr. Ricardo Balbín. Buenos Aires: Fundación Casa Ricardo Balbín, p. 316 y doctrina allí citada.

21 CALAMANDREI, Piero (1997). Elogio de los Jueces, escrito por un abogado, Estudio preliminar de Marcelo Bazán Lazcano, traducción de la tercera edición italiana de Firenze publicada por Le Monnier realizada por Ayerra Redín, Santiago Sentís Melendo y Conrado Finzi. Buenos Aires: Librería El Foro, p. 59 (del Prólogo del autor a la segunda edición). Obvio que no queremos con ello significar que el abogado cumple un rol similar al del juez, en cuanto a su participación en el proceso. El gran autor traído a colación nos dice al respecto que "El abogado que pretendiese ejercer su ministerio con imparcialidad, no sólo constituiría una embarazosa repetición del juez, sino que sería el peor enemigo de éste; porque no llenando su cometido, que es el de oponer a la parcialidad del contradictor la reacción equilibradora de una parcialidad en sentido inverso, favorecería, creyendo ayudar a la justicia, el triunfo de la injusticia contraria”, ob. cit., págs.126 in fine y 127.

22 LEGA, Carlo (1976). Deontología de la profesión de Abogado, traducción de Miguel Sánchez Morón, $1^{\text {a }}$ edición. Madrid: Civitas, p. 45.

23 CUETO RÚA, Julio C., “El buen abogado litigante”, en La Ley, 1988-C-716. 
saba OSSORIO, "Actúa sobre los ciudadanos en su hacienda, en su libertad y hasta en su vida. Está sobre el Gobierno porque enjuicia a sus miembros y porque revoca y anula sus disposiciones en la vía contencioso-administrativa. Impera sobre el mismo Parlamento ya que puede declarar la inconstitucionalidad de las leyes"24.

En definitiva, el abogado debe bregar, además, por la realización del Derecho. Y como dijo magníficamente COUTURE ${ }^{25}$ el día en que se encuentre en conflicto el Derecho -positivo, se entiende- con la Justicia, se debe luchar por la Justicia.
En este aspecto puede válidamente decirse que el abogado -al igual que el político- debe ser ante todo un "filópolis" (al decir de Platón: amante de la polis o sociedad) y debe atender siempre a la realización del bien común, ya que de esta manera, justamente, estaría también alcanzando su bien particular ${ }^{26}$.

Por supuesto que esta importante función (y misión) social atribuida a la profesión forense no puede dejar de influenciar los comportamientos del abogado entendidos según la deontología ${ }^{27}$. Los vínculos entre la mentada función y la éti- ca profesional son tan estrechos que puede válidamente afirmarse que entre una y otra se verifica un proceso de ósmosis ${ }^{28}$.

No podemos dar finiquito a esta cuestión sin atender someramente a un tema de suma relevancia. Nos referimos a la relación entre la clasificación relativa a los sujetos pasivos del comportamiento deontológico y jurídico del abogado con la virtud concreta que potencia dicha realización. En este sentido ha indicado ANDRUET ${ }^{29}$ las siguientes correspondencias: el deber del abogado "consigo mismo" se relaciona con la virtud del estudio ${ }^{30}$; el deber del

24 OSSORIO, Ángel, El alma de la toga, cit., p. 254. Allí continúa diciendo, en opinión que compartimos, que "El juez no puede ser simplemente un profesional porque su misión está situada entre los hombres y los dioses. De nada sirve a los pueblos tener fuerza, riqueza y cultura si no tienen justicia”, ibídem cita anterior.

25 COUTURE, Eduardo J. (1966). Los mandamientos del Abogado, reimpresión inalterada de la $4^{\mathrm{a}}$ ed. Buenos Aires: Depalma, p. 35, mandamiento cuarto: LUCHA. Sinceramente pensamos que no debe egresar un alumno de las Facultades de Derecho -públicas o privadas, española, italiana, peruana o argentina- sin que haya leído tal libro. Pero sobre todo creemos que no debe existir un abogado en ejercicio de su profesión sin que haya comprendido el mensaje que nos legó el gran procesalista uruguayo. Dicho sea de paso, Couture predicó por primera vez sus famosos “mandamientos", con el título Confesiones de un abogado, en Rosario, Argentina, el 17 de junio de 1948. La primera edición del opúsculo Los mandamientos del abogado es de 1949. Ver CHIAPPINI, Julio, Derechos y deberes de los jueces y abogados, ob. cit., pág. 208. Y hablando de mandamientos, también merece un lugar especial, ante todo por la época en que fueron pensados, los de Saint Ive, patrono de los abogados, quien vivió en Francia en el siglo XIII.

26 Se ha afirmado que "Toda profesión tiene siempre el carácter de actividad social. En efecto, la profesión supone una organización social dentro de la cual los distintos trabajos se distribuyen entre los hombres para lograr el bien común. Claro está que esta función social de la profesión está en concordancia con el bien particular de quien la ejerce. Todo trabajo merece su recompensa, que es la ganancia honesta mediante la cual los hombres se proporcionan los medios de su propia subsistencia. La honradez es una consecuencia obligada de la función social de la profesión, que tiene por objetivo el bien común. La profesión es, por su propia definición, una contribución al bien común; de ahí que si una persona busca exclusivamente su propio bien individual, sin importarle los procedimientos, las injusticias, los agravios ni los daños que produce o puede producir a sus semejantes, esa persona será un profesional del crimen, pero nunca un verdadero profesional”, conf. SARMIENTO GARCÍA, Jorge H. (2003). La ética y los jueces. Mendoza:, Ediciones Dike, Foro de Cuyo, Mendoza, p. 83. Obsérvese que el autor recién citado nos habla de una nota común a todas las profesiones, la referida a la 'intención de servir a los demás', característica ésta que adquiere un valor singular en el caso de la abogacía, ello en virtud de los trascendentes intereses en juego.

27 Con criterio general que compartimos, se ha señalado que "Es lógico que la consideración del Abogado como partícipe de un noble ministerio surja un abanico de deberes, y, en su caso, la sujeción a responsabilidad civil, penal y disciplinaria, según el grado de incumplimiento de las tareas profesionales", conforme GARCÍA VARELA, Román, "La conducta desidiosa del abogado y la responsabilidad civil”, en La Ley (España), D-324, p. 2265, diario 4692 de 14 de diciembre de 1998.

28 Conf. LEGA, Carlo (1976). Deontología de la profesión de Abogado, traducción de Miguel Sánchez Morón, $1^{\text {a }}$ edición. Madrid: Civitas, p. 47.

29 ANDRUET, Armando S. (h) (2001). Ejercicio de la abogacía y deontología del Derecho. Córdoba -Argentina-: Alveroni Ediciones, C, p. 67.

30 Se ha señalado que el abogado -al igual que el juez y el maestro de Derecho- debe ser un jurisconsulto o jurisprudente, lo que denota sabiduría del derecho o jurisprudencia. "Prudente" y "consulto" son sinónimos de entendido, maestro, sabio o docto en la ciencia jurídica, "calidades que necesariamente deben concurrir en todos los tipos de actividad del jurista, como son, el abogado, el juez y el preceptor. Sería absurdo, en efecto, que ninguno de estos tipos debiese conocer la ciencia del derecho y que su conocimiento sólo se reservase al jurisconsulto o jurisprudente, pues únicamente el llamado 'legista' puede prescindir de él, toda vez que su 'sapiencia' se reduce a la ley positiva”, conf. BURGOA ORIHUELA, Ignacio (1999). "El maestro de Derecho (magister-juris), en El papel del abogado, Instituto de Investigaciones Jurídicas UNAM. México: Universidad Americana de Acapulco, Porrúa, p. 29. También se ha resaltado la importancia de la investigación 
letrado para con el "cliente" corresponde a la virtud de la honestidad; deber para con el “juez", virtud de colaboración; deber para con los “colegas", virtud de solidaridad; deber con los "cuerpos profesionales", virtud del respeto; deber con la "sociedad", virtud de la Justicia; deber para con la "profesión", virtud de la probidad".

jurídica para el abogado e incluso para el óptimo desarrollo y desempeño de las funciones jurídicos legales de una nación, remarcando que "la investigación jurídica es la que realiza el juez a fin de resolver el caso concreto que se le plantea; lo mismo que el administrador o servidor público para fundar el acto de ejecución de la ley o el legislador en el proceso de creación del derecho, el litigante al formular su libelo y el investigador jurídico en la generación de conocimiento jurídico nuevo", conf. SOBERANES FERNÁNDEZ, José Luis (1999). “El abogado como investigador”, en El papel del abogado, Instituto de Investigaciones Jurídicas México: UNAM, Universidad Americana de Acapulco, Porrúa, p. 171. No resulta abundante transcribir aquí el primer mandamiento de Couture cuando ya proclamaba del abogado que estudie, pues "el derecho se transforma constantemente, si no sigues sus pasos serás cada día un poco menos abogado", COUTURE, Eduardo J. (1966). Los mandamientos del Abogado, reimpresión inalterada de la $4^{a}$ ed., Buenos Aires: Depalma, p. 20. En pocas palabras, no existe autor que no resalte la imperiosa necesidad de que el abogado -igual que otros operadores jurídicos- se dedique a "estudiar", ya el caso sometido a consulta o asesoramiento, ya los principios de su especialidad o de su ciencia en general, o lo que fuere menester para el correcto desempeño profesional.

31 Recomendamos la lectura íntegra del excelente y recientemente promulgado (14/4/2012) Código de Ética del Abogado para el Perú -aprobado por la Junta de Decanos de los Colegios de Abogados del Perú-. Respecto de los deberes que pasamos somera revista en el texto, deben observarse las reglas consagradas en la Sección Tercera y Cuarta (relación del abogado con el cliente); Sección Sexta (relaciones del letrado con las Autoridades); y Sección Séptima (relación del abogado con sus colegas, contraparte y terceros en general). En las Secciones Octava y Novena trata sobre la responsabilidad del abogado y el proceso disciplinario, cuestiones que dejamos para analizar en otra oportunidad, Dios mediante. 